\title{
BIOGRAFIAS DE APRENDIZAGEM NUM ESPAÇO EUROPEU DE MEDIAÇÃO SOCIAL
}

\author{
Rob Evans
}

\begin{abstract}
Resumo
Dentro da estrutura de um projeto Erasmus+ europeu, foram entrevistados mediadores estagiários sobre a sua experiência. Os contactos realizaram-se através de entrevistas não estruturadas, biográfico-narrativas qualitativamente profundas, nas quais indivíduos comprometidos com a interação dialógica criaram um entendimento partilhado, dando significado às suas histórias. Trata-se de entrevistas interativas, co-construídas. O detalhe da linguagem da entrevista documenta como a construção do significado ocorre, e como esta é afetada por motivos de pertença a determinados grupos, por discursos sobre etnias e culturas, assim como pelo género, idade, relações profissionais e educacionais, entre outros. A entrevista é sensível aos recursos da linguagem e aos seus usos na co-construção do significado. Este artigo, usando excertos de uma narrativa biográfica, mostra que a forma falante destas narrativas da aprendizagem biográfica dos mediadores pode oferecer uma visão do processo do conhecimento despoletado pela aprendizagem em comunidades de práticas, e que a criação de um espaço comum de experiência pode ser ouvido na conversa biográfica. Os recursos biográficos, a biograficidade e a sua relação com a linguagem e sociedade são considerados e, nas narrativas da entrevista podem ser observadas, ouvidas e partilhadas a criação de um espaço de aprendizagem, um espaço para o desenvolvimento e a revelação de noções e práticas de mediação.
\end{abstract}

\section{LEARNING BIOGRAPHIES IN A EUROPEAN SPACE FOR SOCIAL MEDIATION}

\begin{abstract}
Within the framework of a European Erasmus+ project, trainee mediators were interviewed about their experience. The encounters took place in unstructured, in-depth qualitative biographical-narrative interviews, in which individuals who are engaged in dialogic interaction create shared understanding and give meaning to their stories. The interview is interactive, coconstructed. The detail of the interview language documents how meaning-making takes place, and how this is affected by group belonging, ethnic or cultural discourses, as well as gender, age, professional and educational relationships, and so on. The interview is sensitive to language resources and their use in the co-construction of meaning. This paper, using extracts from one biographical narrative, shows that the languaged form that these narratives of the biographical learning of mediators take can offer insight into the learning processes triggered by learning in communities of practice, and that the creation of a common space of experience can be heard as it emerges in biographical talk. Biographical resources, biographicity, and their relationship with language and society are considered, and in the interview narratives the creation of a learning space, a space for the development and unfolding of notions and practices of mediation can be observed, heard and shared.
\end{abstract}


KEYWORDS

Biographical-narrative interview; meaning-making; co-construction; biographicity; savoir-vivre; mediation

\section{INTRODUÇÃo}

A chamada de artigos para a conferência internacional organizada pelos colegas do Instituto de Educação e do Instituto de Ciências Sociais da Universidade do Minho, em Braga, convidou trabalhos sobre migração, diversidade, comunicação intercultural e a contribuição da mediação para a promoção de uma sociedade civil pacífica, segura, inclusiva e aberta. Na resposta à chamada, neste artigo procura-se analisar as biografias de aprendizagem de profissionais da mediação social participantes no projeto de três anos (2017-2019) Erasmus+ CreE-A (Construction d'un espace européen de la Médiation sociale pour l'inclusion)' de forma a discutir a contribuição que esta narrativa biográfica pode dar para a compreensão da formação da identidade e prática do mediador.

O último e mais ambicioso objetivo do projeto CreE-Arlekin é a criação de uma comunidade profissional para a mediação social na Europa. Um consórcio europeu com diferentes parceiros, incluindo organizações para a mediação e a formação, universidades, cidades, especialistas na teoria e prática da mediação, assim como representantes políticos nacionais e europeus, que trabalhem juntos no projeto para estabelecer um intercâmbio estruturado entre a prática e a teoria da mediação europeia. O objetivo a curto e médio prazo do CreE-A é identificar as práticas comuns de mediação social, e promover a consciência e o conhecimento destas práticas, assim como o respeito pela diversidade da sua realização nos contextos específicos de cada país (Silva, Carvalho, Moisan \& Fortecöef, 2017).

O aspeto principal do projeto é a Tour d'Europe, uma viagem de aprendizagem experimental inspirada nas tradições dos artesãos europeus. Em 2017, o primeiro ano deste projeto, 14 profissionais da mediação (ou profissionais de práticas próximas à mediação) foram enviados de país a país, dentro dos sete países participantes, numa jornada de imersão nas realidades do trabalho dos mediadores, participando reflexivamente numa "viagem através da Europa, durante a qual cada participante conheceu e partilhou experiências biográficas e profissionais, enquanto mediador, com outros mediadores-profissionais de diferentes países" (Silva et al., 2017, p. 75). Cada participante trouxe consigo a sua experiência prática e conhecimento prévios e cada um foi confrontado durante o período de imersão com colegas mediadores que os receberam e lhes forneceram um espaço de aprendizagem onde conseguiram comparar e confrontar diferentes práticas, e no qual foram trocadas diversas biografias de aprendizagem e conhecimentos, tanto formais como tácitos.

Paralelamente a esta imersão prática na realidade dos processos de mediação dos seus pares, aos participantes foi requerida uma reflexão sobre as suas biografias pessoais e profissionais. Os coordenadores do projeto forneceram-lhes as ferramentas de reflexão necessárias para os ajudar a identificar conhecimentos e experiências 
profissionais diversas, para avivar a sua consciência sobre a prática da mediação para a inclusão social no país anfitrião, para observar e descrever as práticas de mediação encontradas e para reportar estas questões através de um relatório multimédia para concluir com sucesso a sua participação no projeto (o Chef d'Oeuvre, Obra-Prima), avaliado por um Júri de Especialistas no final de 2017, em Barcelona.

\section{A PESQUISA: INVESTIGAÇÃo DE UMA BIOGRAFIA DE APRENDIZAGEM}

Durante o seminário final em Barcelona, oito dos participantes (cinco profissionais da mediação e três mediadores especialistas) foram entrevistados sobre a sua experiência durante a Tour d'Europe e o impacto do espaço europeu na mediação social de acordo com a sua experiência durante a imersão no país anfitrião. Os contactos com os mediadores-participantes realizaram-se através de entrevistas não estruturadas, biográfico-narrativas qualitativamente profundas, nas quais indivíduos comprometidos com a interação dialógica criaram um entendimento partilhado, dando significado às suas histórias. As suas histórias narrativas tornam-se compreensíveis, para citar Luckmann, pelo processo de união de "experienciar as experiências dos outros" (Luckmann, 1981, p. 58). A entrevista é interativa, co-construída e formada por vozes, as vozes dos co-investigadores e de outros cujas palavras são usadas e relembradas pelos oradores. O detalhe da linguagem da entrevista documenta como a construção do significado ocorre, e como esta é afetada por motivos de pertença a determinados grupos, por discursos sobre etnias e culturas (Pavlenko, 2007), assim como pelo género, idade, relações profissionais e educacionais, entre outros. A entrevista é sensível aos recursos da linguagem e ao seu uso na co-construção do significado, pelo que o mais adequado foi conduzir as entrevistas de Barcelona nos idiomas dos próprios participantes, nomeadamente Francês, Italiano, Português e Alemão.

Neste artigo, usando excertos de uma narrativa biográfica, vou tentar mostrar que a forma falante destas narrativas da aprendizagem biográfica dos mediadores pode oferecer uma visão do processo do conhecimento despoletado pela aprendizagem em comunidades de práticas e que a criação de um espaço comum de experiência pode ser ouvido na conversa biográfica. Este artigo tem a seguinte estrutura:

- em primeiro lugar, vou considerar algumas das condições necessárias para qualquer discussão de linguagem falada e o seu uso como "dados". Em particular, é necessário estabelecer algum cuidado em relação ao uso de transcrições com base na conversa das entrevistas multilingues;

- em segundo lugar, serão considerados os recursos biográficos e a sua relação com a linguagem e a sociedade, do ponto de vista da intersubjetividade e da linguagem como ação;

- em terceiro lugar, será apresentada uma breve discussão sobre a biograficidade e a relevância dos dados da linguagem que são produzidos na narrativa biográfica que será analisada;

- e, por último, as minhas conclusões vão tentar sublinhar as vantagens da abordagem da linguagem discutida aqui, destacando o processo de aprendizagem contínuo contado nas narrativas da história de vida dos mediadores. A criação de um espaço de aprendizagem, um espaço para o desenvolvimento e a revelação de noções e práticas de mediação que podem ser observadas, ouvidas e partilhadas; 
- a conversa de Butoyi (nome alterado por questões de anonimato), uma das mediadoras entrevistadas em Barcelona, em 2017, será seletivamente analisada.

\section{UTILIZAÇÃO DE ENTREVISTAS QUALITATIVAS PARA COMPREENDER O MEDIADOR}

As entrevistas qualitativas de pesquisa relacionam-se com a experiência individual e de grupo da realidade social e observam, questionam e gravam o testemunho dos próprios atores em locais de interação social escolhidos para a recolha dos dados e a sua posterior análise. A relação entre os atores sociais que participam em processos de transição e transformação em contextos sociais, profissionais e pessoais muito diferentes e o investigador, tem sido central para a discussão dos métodos e dos objetivos de pesquisa ao longo de vários "ciclos" metodológicos nas últimas décadas (Merrill \& West, 2009).

Existem diferentes abordagens para a entrevista biográfica e para as narrativas centradas em histórias de vida. Como indicado acima, eu proponho o uso da entrevista discursiva-biográfica, a qual se foca na construção do significado falante no discurso interativo das narrativas biográficas. Outras áreas de pesquisa de biografia e de história de vida devem necessariamente ser excluídas desta breve discussão, apesar do seu valor teórico e empírico não estar em causa (ver por exemplo Alheit, 2002; Bertaux, 2005; Dausien, 1996; Demetrio, 1995; Fuchs-Heinritz, 2000; Merrill \& West, 2009; Pineau \& Le Grand, 2007; Schütze, 1976, 1981).

Os inquiridos na entrevista de pesquisa que participam em diversos ambientes, como os profissionais da mediação entrevistados em Barcelona, oferecem uma visão das entrevistas discursivas não estruturadas na importância dos processos de alteração crítica para o seu conhecimento individual e coletivo. E, ao fazer isso, eu discuto aqui que eles podem ser ouvidos na construção de discursos próprios de aprendizagem, nos quais a aceitação de, e a resistência aos discursos dominantes das instituições e da sociedade civil é abandonada na estratificação interdiscursiva de interação com (a) a própria narrativa contada, (b) com a agenda do investigador e (c) com o diálogo, muito importante com aqueles cujas vozes e narrativas dão expressão à complexidade e aos significados transacionados dos contextos de aprendizagem individuais e de grupo. $O$ mediador traz para o seu trabalho e para a sua conversa uma história pessoal, uma história de família, uma história de aprendizagem e uma história de escolhas de vida, para referir apenas alguns dos aspetos críticos no desenvolvimento de um indivíduo.

\section{CONVERSA BIOGRÁFICA, TRANSCRIÇÃo, TRADUÇÃo E APRESENTAÇÃo}

Antes de passar à análise das partes da narrativa aqui apresentada, são necessárias algumas palavras sobre a utilização das transcrições da entrevista na pesquisa biográfica. Está amplamente reconhecido que a decisão de um determinado nível de detalhe na reprodução da entrevista falada, ou a omissão de alguns detalhes, representa o nível fundamental de análise decidido (Gülich \& Mondada, 2008; Ochs, 1979). Assim como 
a análise dos tempos, volume, entoação, stress e prosódia, entendidas como produtos e produtores essenciais da interação e da co-construção de significado (Günthner, 1997; Szczepek Reed, 2011).

A apresentação dos dados e das descobertas impõe alguns obstáculos interessantes de ultrapassar. Devido às dificuldades técnicas em apresentar entrevistas em diferentes idiomas numa tradução literal, devido à enorme diferença entre as estruturas sintáticas, os problemas morfológicos inerentes, para não mencionar a natureza problemática da exemplificação das características de significado e de discurso através do recurso a traduções descontextualizadas, por regra, a tradução é utilizada apenas para permitir o acesso à discussão dos fenómenos do discurso em diferentes idiomas. Neste sentido, quaisquer tentativas de apresentar os elementos prosódicos do discurso, devem ser sempre entendidas como a realização de uma função estritamente impressionista. Neste artigo, os excertos da conversa apresentados foram mantidos no idioma original: o Francês. Os comentários e a discussão da conversa da entrevista referem-se sempre ao idioma original.

Relativamente à transcrição/apresentação da conversa, em pesquisas deste tipo devem ser observadas as exigências de exatidão em relação ao idioma original da interação e, como consequência, às pragmáticas interculturais do processo de receção e à explicação dos resultados da análise. Aneta Pavlenko (2007) apontou que quando se trata de trabalhar com entrevistas multilingues, ou de trabalhar com mais que um idioma, tanto no processo de entrevista como no processo de pós-produção da apresentação e disseminação, deve ser levada a sério a imagem completa da riqueza linguística da narrativa e todas as implicações de trabalhar num idioma ou noutro (Pavlenko, 2007).

Por esta razão, é necessário explicar brevemente o método utilizado aqui para apresentar o discurso e o formato básico da transcrição. Relativamente à questão de coloquialidade perante qualquer tipo de representação "ideal" do discurso, eu optei aqui por uma transcrição que ignora a pronúncia individual e a elisão natural, fornecendo uma versão ortograficamente "normal" da conversa ouvida. Por outro lado, as formas de pontuação da escrita padrão foram omitidas por ser externas ao discurso. No seu lugar, existem indicações de subida e descida de tom (? e _), pausas, respiração (inspirações .h e expirações h), falar alto (em MAIÚSCULAS), etc. Não foi feita nenhuma tentativa de forçar a conversa num tipo de "forma", como parágrafos, nem de usar dois pontos, travessões ou qualquer outra forma de organização lógica. As pausas curtas são indicadas por (.) e as pausas mais longas foram livremente cronometradas em segundos (2.0). As hesitação ou dúvidas são indicadas por "uhh". As passagens ininteligíveis da gravação da entrevista são assinaladas com (xxx).

Cada excerto da transcrição (TS) é apresentado em Francês, com a forma de uma tabela, como se segue.

\begin{tabular}{lc}
$\begin{array}{l}\text { N. }{ }^{\circ} \text { da linha } \\
\text { do excerto }\end{array}$ & TS Francês $\quad$ Comentário sobre a estrutura da narrativa e o trabalho interativo \\
\hline & Tabela 1: Apresentação dos excertos de transcrição
\end{tabular}


A coluna 1 mostra o número da linha dentro do excerto atual. A coluna 2 inclui o TS original em Francês. A coluna 3 contém informação relevante para a análise do TS como uma narrativa. Por exemplo, esta coluna pode conter referências sobre características do discurso (p. ex. discurso epistémico $(\rightarrow$ EpD), prosódia $(\rightarrow$ Pro), modalidade $(\rightarrow M P)$ ou correções ou hesitações ("self-repair" $\rightarrow$ SR). A coluna 3 também pode incluir informações de conversão, onde as conversões ou modificações específicas são realçadas e discutidas na análise. A referência ao "discurso embutido" (ESp) tem particular importância nesta compreensão da natureza da expressão dos discursos biográficos.

Linde assinala como as histórias de outras pessoas (relacionadas no discurso indireto, embutidas e sobrepostas na narração) se tornam histórias "pessoais", através de um processo de apropriação ou conversão (Linde, 1993, p. 35). O estado descontinuado e inacabado da narrativa oral é assim incorporado no discurso utilizado pelo narrador autobiográfico. Aqui, o conceito de "embutir" de Goffman pode ser usado para descrever este aspeto do "eu" do orador. As palavras que dizemos, aponta o autor, "não são frequentemente as nossas, pelo menos as "nossas" atuais", pelo que "apesar de que quem fala se encontra situacionalmente circunscrito, a pessoa em cujo nome são ditas as palavras de certeza que não o está" (Goffman, 1981, p. 3). Assim, esta incorporação torna possível "adotar" numerosas vozes através do espaço e do tempo dentro da estrutura interativa da narrativa oral e da entrevista narrativa (Goffman, 1981, p. 4). Isto, como tentarei mostrar mais à frente na análise dos dados, é uma caraterística central da conversa interativa na entrevista de pesquisa. De facto, para o desenvolvimento de discursos "próprios" dentro de uma biografia de aprendizagem emergente, as palavras "convertidas" e "adotadas" de outros, ou de um "eu" não atual - aquilo a que chamo "discurso embutido" - são um importante dispositivo para a contextualização da conversa e servem como um dispositivo para fundamentar a validade da conversa, dando-Ihe autoridade (Evans, 2004).

\section{RECURSOS BIOGRÁFICOS: LINGUAGEM E INTERSUBJETIVIDADE, A LINGUAGEM E “O MUNDO"}

A experiência biográfica está sempre ligada a um contexto específico, e a experiência nova é trabalhada e retrabalhada na história de vida anterior. As "experiências biográficas e o conhecimento biográfico que surge através das mesmas", como afirma Hoerning, "não são meramente o abandono de uma camada de coisas experienciadas, mas também o refazer contínuo de tudo o que é experienciado" (Hoerning, 1989, p. 154). As biografias narradas através de encontros são peças descontínuas e a conversa, como poderemos ver mais à frente, é conversa biografada, a qual é estruturada tanto temporalmente como sequencialmente, realizando na comunicação interativa o refazer da experiência da qual fala Hoerning. Ochs e Capps expressam-no deste modo:

a narrativa pessoal é uma forma de usar a linguagem ou outro sistema simbólico para incorporar eventos de vida com uma ordem temporal e lógica, para os desmistificar e estabelecer uma coerência entre o passado, o presente e as experiências ainda não realizadas. (2001, p. 2) 
A "mudança radical" da "conversão linguística" dos anos 1960, orientada para o interesse de um conhecimento "revelador, socialmente coordenado, temporalmente e espacialmente situado" das práticas, atividades e ação mediadas da linguagem (Schegloff, Ochs, \& Thompson, 1996, p. 6) impulsionaram a noção de articulação da investigação e de construção coletiva do significado, através da comunicação intersubjetiva que se focava na perspetiva do sujeito da pesquisa (Hoffmann-Riem, 1994; Schiffrin, 2006; Schütze, 1975). A realização do significado na interação entre contextos (social, institucional, físico ou emocional, entre outros) é conseguida, nesta perspetiva, através da revelação sequencial dos recursos interativos dos membros dos diversos cenários no discurso "com outros para além deles próprios e em última instância com o mundo" (Ricoeur, 1995, p. 41). Os contextos mais amplos nos quais os participantes estão ativos são compreendidos aqui como, nas palavras de Gale Miller, "ecologias de conhecimento" interligadas, nas quais se organizam os significados interacionais específicos de uma situação (Miller, 1994, p. 168). Sob este ponto de vista, os sujeitos são capazes de fazer uso dos recursos de diferentes cenários, socialmente organizados, aos quais pertencem (ou, por exemplo, nos quais se posicionam como pertencentes), de forma a se constituírem e reconstituirem discursivamente a si próprios e aos cenários institucionais com que interagem.

Assim, os processos discursivos de construção da identidade dão-se na interação da linguagem em vários, múltiplos, níveis. $A$ interação e as relações de reciprocidade entre os indivíduos e os outros fornece a estrutura dentro da qual os "eus" são construídos na comunicação com os outros. A relação mutável dos indivíduos com as suas palavras e as dos outros, atuais ou antigas, influenciam todos os passos da construção da identidade. A linguagem, disponível para os indivíduos sob várias formas, permite- Ihes descreverem-se a si próprios e ao mundo, assim como às relações sociais dentro (e a desassociação de) de grupos reconhecíveis. As diferentes relações de associação e de pertença a um lugar, a um grupo étnico, a grupos socialmente aceites ou socialmente estigmatizados - uma profissão respeitada, uma comunidade de gueto, uma comunidade religiosa - são construídas em conversa através da indexicalidade. Neste sentido, são criadas identidades "localizadas" ou globais, que constantemente se cruzam no discurso dos oradores (De Fina, Schiffrin \& Bamberg, 2006).

Silva, Carvalho e Aparicio (2016) salientam que a formação de mediadores profissionais é um processo que envolve a interação com os outros, com o contexto social da ação de mediação, assim como um processo de reflexão e ação pelo indivíduo em si próprio no processo da sua formação. O resultado do processo é, afirmam, "um processo de construção dinâmico, interativo, contextualizado e contínuo". Adicionalmente, de acordo com um grande número de publicações, argumentam que é um

processo individual, no qual a imagem e a definição de cada um (história e identidade pessoal) e dos outros (identidade social) são configuradas em relação com o reconhecimento (pontos de referência, associação, atributos, identificações, estado coletivo) garantido por outros membros da família profissional. (Silva et al., 2016, p. 94) 
Assim, os sujeitos usam os seus recursos biográficos formados na ação social, de forma a constituir-se discursivamente a si próprios e aos cenários pessoais e profissionais nos quais interagem. Butoyi, participante no projeto cuja conversa será agora considerada, apresenta evidências deste elemento da história de vida.

Foi-lhe pedido que falasse sobre a sua educação e a sua escolha de carreira. Quando lhe perguntaram porque é que tinha escolhido Direito, Butoyi respondeu:

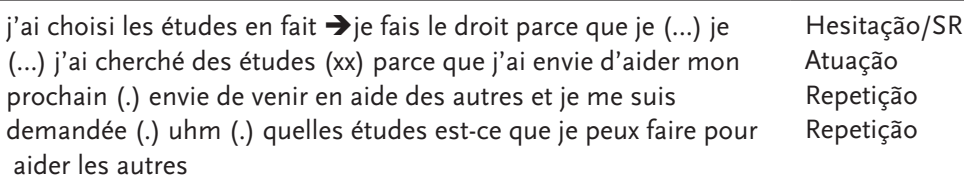

Tabela 2: Excerto 1

Pensa, atrasa cuidadosamente a sua resposta (indicado como discurso de hesitação/correção em 1.1) e, a seguir, formula uma afirmação forte na primeira pessoa, utilizando muito a repetição ("envie d'aider"; "venir en aide"; "pour aider"; II. 2-4). Devido à ênfase com que ela evidentemente deseja sublinhar o seu desejo de ajudar, é-lhe perguntado porque é que escolheu Direito para ajudar os outros. Butoyi afirma que estava à procura de algo diferente daquilo que já faziam a sua mãe (enfermeira) e as suas irmãs: “j'ai cherché quelque chose de différent pour ne pas faire la même chose ...".

E continua:

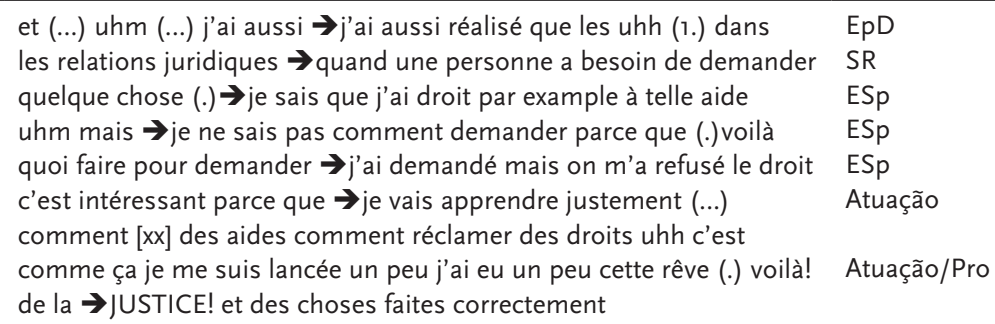

Tabela 3: Excerto 2

Butoyi desliza na sua narrativa para uma forma e voz de um Outro anónimo. O seu desejo é claramente expressar e justificar a sua insatisfação com os "assuntos legais" do dia-a-dia. Alguém que precisa de informação ou ajuda legal acaba muitas vezes por sentir-se bloqueado ou rejeitado pelas rotinas normais da Lei, argumenta. Esta afirmação de Butoyi recebe uma voz de "fora do palco" (indicado como ESp), uma voz na primeira pessoa, uma afirmação imediata de veracidade e urgência. Este uso do discurso embutido de um Outro Desconhecido serve aqui para justificar os avanços hesitantes do ponto de vista da própria Butoyi. O que ela pretende é "Justiça". A emotiva simplicidade da Justiça é cuidadosamente parafraseada: para "ver as coisas feitas da forma correta". A linguagem prosódica enfática, aproveitando o volume e a energia, é assim enquadrada pelo aumento do detalhe tipo-ficção e pela retórica conscientemente sóbria. Butoyi utiliza o contexto da sua experiência de forma natural e habilidosa, para construir uma mensagem narrável, criando uma narrativa com significado e partilhável. 
As bases da família de Butoyi representam um papel nos valores expressos por ela. O seu avô foi diretor de uma escola no Burundi. A experiência da imigração, da chegada à Bélgica, não foi isenta de relevantes dificuldades.

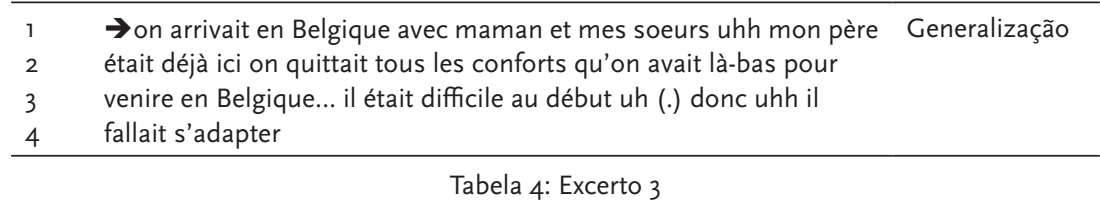

Butoyi observa que, por comparação, as suas sobrinhas agora já não têm problemas. Os seus pais deram-lhe tudo o que podiam. Para ela pessoalmente, e para a sua família, a adaptação foi mais difícil no início. Sob a pressão de um ambiente estrangeiro e novo na Bélgica, "on a dû readapter ici, refaire les études". Esta pressão sobre os membros mais jovens da família significou que "on mature un peu plus rapidement". Perante decisões impostas pelo contexto no qual eram obrigados a "crescer rapidamente", Butoyi diz, "on réflechissait, on a dû réflechir un peu plus vite que les autres".

Nestas afirmações é claramente percetível o uso repetido do pronome impessoal. Isto permite que o orador recue para um segundo plano. É apresentada em primeiro plano a experiência geral e generalizada da sua família. A narrativa epistémica é assim generalizada. Adicionalmente, com "fallait s'adapter" e "a dû readapter" é-nos dado a compreender que a família, e a própria Butoyi, foram obrigadas pela força das circunstâncias. Parece que a perda forçada de atuação é mais do que compensada pelo ato de afirmação do próprio agente e pelas afirmações de conhecimento que Butoyi procura estabelecer.

Não recebemos apenas a relação de uma verdade generalizada válida, mas podemos, em apenas alguns segundos de conversa, começar a ouvir o poder da repetição ("un peu plus", "on a dû readapter", "on réflechissait", "on a dû réflechir") que estiliza tão fortemente a conversa retórica (Tannen, 2007, p. 9).

Isto ajuda a justificar o sentimento de insegurança que é afirmado e dá cor à narrativa com elementos de força, necessidade, mas também de resiliência. Butoyi continua a relacionar com entusiasmo a história de como com 12-13 anos ficou responsável por fazer as compras para a família quando a mãe estava a trabalhar. Aquilo que, sugere, é considerado por muitos um escândalo, foi para ela uma experiência que lhe deu energia, resiliência e maturidade. Esta curta peça da narrativa começa com "je me souviens". E completa a pequena história com as palavras "moi, j'aimais bien cette autonomie là". Neste ponto particular da narrativa, Butoyi surge com mais vigor na sua narrativa, deixando de utilizar "on" e começando a falar na primeira pessoa.

\section{RECURSOS BIOGRÁFICOS E ESTRUTURAS QUOTIDIANAS DE EXPERIÊNCIA NA HISTÓRIA DE VIDA}

O método biográfico permite-nos assim questionar como a mudança nos ambientes das pessoas é reconhecida subjetivamente pelos indivíduos, e como tal mudança 
influencia a aprendizagem em situações de vida/trabalho/aprendizagem. Histórias de vida, de acordo com Alheit (1983), são essencialmente preenchidas pela necessidade de sincronizar níveis díspares de tempo experienciado: primeiramente, as dimensões de eventos e experiências enquadradas como rotina, o dia-a-dia, e aquelas que operam no horizonte/escala do tempo de vida, os quais "conectam eventos há muito passados com experiências passadas, experiências passadas com as presentes e finalmente o presente com possíveis eventos futuros" (Alheit, 1983, p. 189). Refazer a reserva de experiências com as experiências recentes e criar novas associações entre o novo e o já vivido, significa que o narrador tira partido dos seus recursos biográficos recolhidos e estratificados. Podemos ver estes recursos como a totalidade do indivíduo ou a essência de vários e diferentes processos de aprendizagem. Eles são o resultado do significado individual dado à experiência, que produz formas subjetivas de conhecimento. Este conhecimento, por sua vez, é a base de novas estruturas culturais e sociais de experiência. Esta prática social de aceder (e construir) recursos biográficos ao longo da vida, de forma a alcançar os requisitos quotidianos de um curso de vida mais orientado individualmente, tem sido apelidado de "biograficidade" (Alheit, 1990, 2018; Alheit \& Dausien, 2002).

Já vimos como Butoyi fala da sua infância e juventude, em termos de autonomia e responsabilidade. Os seus estudos são caracterizados, ao longo da sua narrativa, como uma procura de um propósito. Aos 16 ou 17 anos conheceu uma mulher que era juíza. $\mathrm{O}$ desejo de Butoyi de "ajudar os outros" levou-a a estudar Direito durante três anos. Mas estes estudos não foram satisfatórios. No seu terceiro ano na universidade de Direito, ficou a conhecer a mediação nos tribunais. Aqui, experienciou o confronto dos acusados com as vítimas das suas transgressões e a responsabilização dos acusados, induzindo uma consciência da infração pela qual eram acusados. A sua reação foi:

\begin{tabular}{cll}
\hline 1 & et $\rightarrow$ je me suis dit vois ça c'est une bonne manière intéressante & ESp \\
2 & d'aider l'autre parce que l'homme $\rightarrow$ j'éspère il va plus recommencer & EpD \\
\hline Tabela 5: Excerto 4
\end{tabular}

Butoyi reproduz aquilo que ela apresenta como os seus processos genuínos e espontâneos de pensamento neste momento passado. Este imediatismo torna a posição tomada menos vulnerável, uma vez que não é apresentada como um argumento lógico, ou como uma conversão no diálogo (com qualquer um). Assim, este uso do discurso embutido bastante comum (ESp) é utilizado para definir a própria agenda do narrador e serve também para apoiar a afirmação epistémica seguinte, nomeadamente, que, com a intervenção adequada, um infrator - generalizado como l'homme - não irá repetir a infração. Há uma crítica do sistema legal, mas há também um reconhecimento de que a solução imediata é frequentemente substituída por dificuldades legais com a perda do diálogo ou da interação entre o "acusado" e a "vítima". Contudo, ela pensou ter conseguido ver o potencial da utilização desta mediação "win-win": 


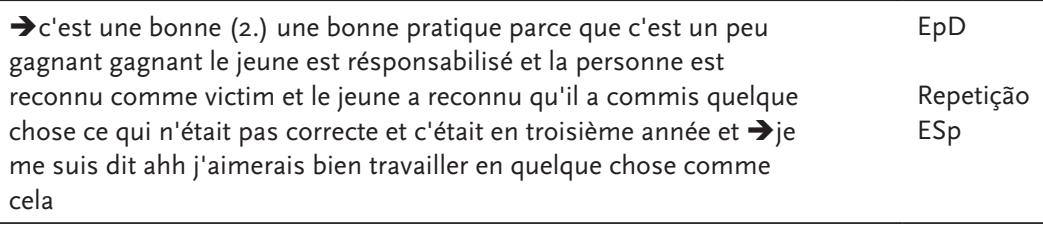

Tabela 6: Excerto 5

Uma vez mais, nestes curtos excertos da sua detalhada narrativa de encontrar a sua forma um pouco sinuosa de apresentar o seu compromisso com as práticas de mediação, é evidente, ao nível mais simples de ouvir, como constrói "cadeias" de discurso narrativo, nas quais as suas afirmações com caráter epistémico ("c'est une bonne manière intéressante d'aider l'autre parce que" I.1-2; "c'est une bonne pratique parce que" I.3) são repetidas com ligeiras variações, seguidas de formas sintáticas firmes e fixas. $O$ efeito global da sintaxe nestas passagens da conversa é voluntariamente simples, com a utilização de verbos simples e ativos, produzida em progressões do tipo lista. Isto ajuda à coerência, as afirmações são construídas sequencial e cumulativamente. Aparentemente, o objetivo é declarar uma certeza, protegendo-se contra possíveis críticas. O efeito global é coroado com - ou leva a - o acentuado uso do discurso embutido (Excerto 4 l.1, Excerto 5 l.4-5). Butoyi desvia-se sem esforço de um tipo confiante de discurso epistémico, no qual afirma a sua aprovação da mediação nos tribunais para o efeito "tempestade" que isto teve no seu próprio raciocínio: “je me suis dit ahh? j'aimerais bien travailler en quelque chose comme cela?" Butoyi está mais uma vez a interpretar os seus pensamentos daquela altura do passado na forma de discurso direto interior, para emprestar força e vigor à afirmação de conhecimento que faz neste momento sobre o valor da mediação (e, por isso, sobre a "justiça" ou "lógica" da sua presente trajetória no momento do discurso).

Enquanto Butoyi está aqui, a falar sobre sítios, tempos e eventos ligados entre si no passado, Daniel Bertaux argumenta que "existe uma história de vida logo quando alguém conta a alguém, quer seja um investigador ou não, qualquer episódio da sua experiência vivida" (Bertaux, 2005, p. 36), uma vez que a consideração discursiva assume uma forma que é relativamente espontânea e dialógica (Bertaux, 2005).

Nas narrativas suportadas por "gramáticas" de experiência falada, é vocalizada e construída uma determinada ordem e coerência. Estas - histórias recorrentes, uso repetido da linguagem, por exemplo - são usadas para construir teorias de eventos que emergem como efetivas biografias negativas ou positivas (Capps \& Ochs, 1995). Lisa Capps e Elinor Ochs usam o termo "gramática" no seu estudo sobre um doente com agorafobia "para cobrir amplamente como o narrador junta palavras em sequências (sintaxe), como as próprias palavras são estruturadas (morfologia) e o sistema de som (fonologia) que os narradores usam para criar significado" (Capps \& Ochs, 1995, p. 52).

A narrativa da história de vida de Butoyi (que também se aplica às outras entrevistas) oferece exemplos da cor da sua narrativa, através de elementos específicos de linguagem, elementos que carregam sinais importantes de interpretação e de construção de significado. 
Para Butoyi, o seu contacto com a mediação e com a reunião dos profissionais da mediação com outros colegas no início do projeto CreE-A foi um "choque". Colocar em prática o que aprendeu é um desafio e uma aventura. Butoyi sente a necessidade de enfatizar a sua falta de experiência. É a única estudante entre os participantes no projeto, afirma, e eles trabalham na área da mediação há décadas, enquanto ela está apenas a "estabelecer-se" ("moi je débarque"! I.6). A narrativa neste excerto é notavelmente produzida como um diálogo próprio na primeira pessoa. Mas o que nos é pedido é ouvir o pensamento de Butoyi no ponto particular do passado, quando estas experiências aconteceram. O imediatismo da voz na primeira pessoa dá veracidade e autoridade ao seu argumento e, ao mesmo tempo, mostra a necessidade de considerar em detalhe a posição que ela assume. Isto torna a narrativa autêntica e auto-orientada, credível e incontestável.

\begin{tabular}{|c|c|c|}
\hline 1 & c'est une aventure parce que $\rightarrow$ je me suis dit avant je vais déjà & ESp \\
\hline 2 & $(x x x)$ et apprendre comment ils font la mediation dans les autres & \\
\hline 3 & pays et même déjà à la reunion à Seville quand j'ai entendu uhh & ESp \\
\hline 4 & $\rightarrow$ tu n'es pas professionelle parce que moi je suis la seule & \\
\hline 5 & ÉTUDIANTE là-bas uhh oui oui les autres travaillent déjà pendant & \\
\hline 6 & dans les structures ça fait 15 ans 20 ans qu'ils sont dans la mediation & Pro \\
\hline 7 & $(.) \rightarrow$ moi je DÉBARQUE? hahaha uhh et après $\rightarrow$ je me suis dit & ESp \\
\hline 8 & mais c'est intéressant de voir uhh voir comme est-ce que eux font(1) & \\
\hline 9 & parce que est-ce que j'ai bien (xxx) le projet creea c'est uhh & Repetição \\
\hline 10 & apprendre des autres apprendre ce que les autres font comme ça (1) & \\
\hline 11 & découvrir aussi peut-être comme eux ont une manière de faire que & ESp/Atuação \\
\hline 12 & je ne connais pas et $\rightarrow$ je vais l'apprendre et la mettre en pratique en & \\
\hline 13 & rentrant chez moi parce que je l'ai bien aimée et voilà s'enrichir de & \\
\hline 14 & de l'expérience de ça là est l'aventure (.) au lieu de rester entre & \\
\hline 15 & guillemets enfermée dans la pratique belge en belgique $100 \%$ belge & \\
\hline
\end{tabular}

Tabela 7: Excerto 6

Continua, destacando o maior impacto da experiência direta comparado com a leitura e o estudo. Pode-se aprender através de um livro ou da internet, mas:

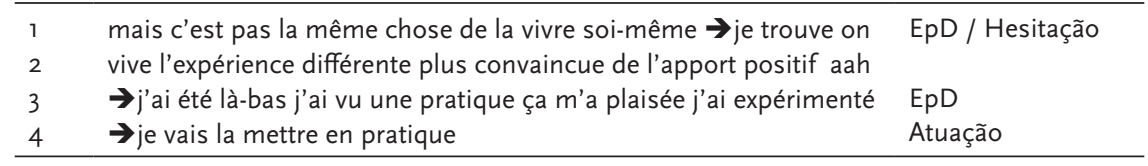

Tabela 8: Excerto 7

Enquanto a informação e os livros permanecem distantes, a experiência direta que adquiriu significa que esta é vivida a "cem por cento": "on la vit à 100 percent on est plus convaincue - je trouve". O choque do seu primeiro encontro com a mediação social, no entanto, foi perceber que fazer mediação é difícil ("être médiateur n'est pas facile!").

\section{"BIOGRAFICIDADE", ATUAÇÃo E REFLEXIVIDADE BIOGRÁFICA}

Para ser capaz de desenvolver em conversa uma narrativa própria mais coerente em termos de linguagem para se "traduzir" a si mesmo - é crucial ter acesso a espaços 
de aprendizagem nos quais os recursos biográficos podem ser adquiridos e implementados, e que, por sua vez, definam como se interpretam a experiência e o senso comum. "Biograficidade", segundo a visão de Alheit (Alheit, 2006) significa a vontade ou necessidade (assim como a possibilidade) de obter tais recursos da experiência através do exercício da atuação na modelação das nossas vidas. Gaston Pineau também sublinha a essência de saber como viver ("pouvoir-savoir vivre") e as dificuldades sentidas por toda a gente para ser agente e levar para a frente o projeto das suas vidas. Pelo que afirma: "todo ser é um cogito que, ao mesmo tempo, se molda a si próprio, formando-se apenas o melhor que consegue" (Pineau, 1996, p. 78).

Assim, uma abordagem biográfica que analise a identidade atuante como um recurso para dar sentido às experiências de aprendizagem e, mais simplesmente, como Pineau sugere, para sobreviver no mundo (1996, p. 78) vira a nossa atenção enquanto investigadores e profissionais da educação para o que acontece nas fronteiras entre a vida vivida e a vida refletida, ou "frontières biocognitives", nas palavras de Pineau (1996, p. 78).

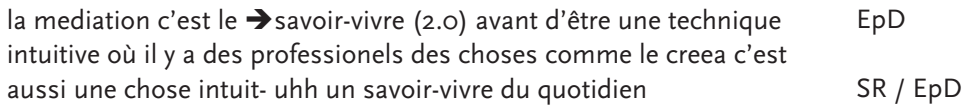

Butoyi expressa uma ideia bastante próxima da noção de aprendizagem biográfica utilizada por Gaston Pineau. A experiência em uma ou duas escolas da Bélgica com a mediação mostra, nas suas palavras, a natureza da mediação como um "savoir-vivre", um processo de sensibilização dos estudantes que, naturalmente, não é uma tarefa fácil ("ca prend du temps"). A experiência coletiva dos mediadores estagiários e dos seus formadores dentro do projeto CreE-A, no qual podem ser forjadas ligações tipo família, permite-Ihe esperar que os efeitos práticos da mediação como um projeto, como um savoir-vivre, possam crescer.

"Ser um estrangeiro", uma mulher, um homem tem lugar ao nível do "quotidiano", enquanto a alteridade biográfica, de género ou classe, por exemplo, deve ser entendida num sentido de "vida". Ser um mediador, intervir em momentos de conflito entre estranhos, pessoas oriundas de contextos de vida, práticas linguísticas e usos comportamentais completamente diferentes, molda o processo de atuação nas fronteiras do quotidiano e da vida. Como já foi dito (Silva et al., 2016, p. 94), a construção biográfica do mediador é tanto um ato como um processo reflexivo. À medida que a vida se desenvolve, em cada viragem da vida vivida, Bettina Dausien sugere que "são vividas novas experiências, onde o sujeito tem de integrar um "eu" já existente, e construções do mundo, e, como resultado, estas são confirmadas e estabilizadas (reprodução) ou alternativamente devem ser "reescritas" (transformação)" (Dausien, 1996, p. 574).

Butoyi relata as dificuldades vividas na sua fase de imersão na experiência com mediadores experientes, lidando com famílias e com os seus problemas diários de ter de pagar contas de gás e eletricidade, manter os seus apartamentos, as dificuldades 
em perceber e ser percebido. As emoções são difíceis de gerir, mas este é um caminho que ela tomou, uma atividade na qual tenta começar a ter sucesso. Contudo, existem limitações.

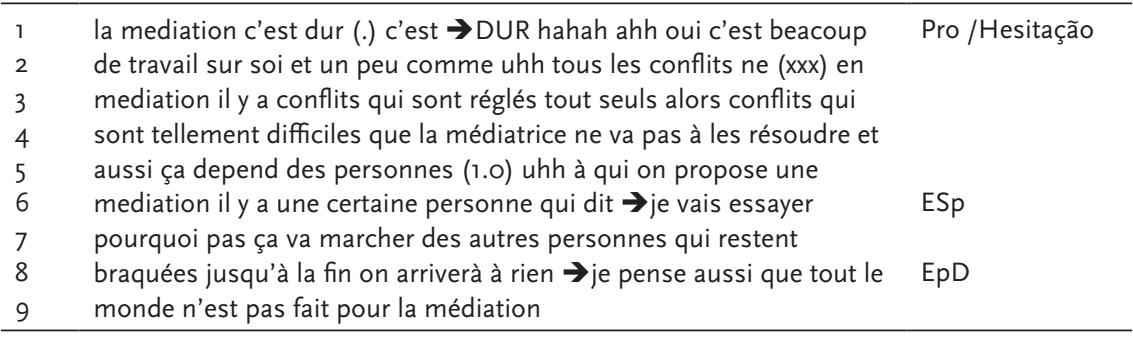

Tabela 10: Excerto 9

Butoyi admite que as dificuldades que o mediador enfrenta não são insignificantes. A sua insegurança neste tópico pode ser ouvido nos efeitos prosódicos do aumento do volume e da ênfase (Pro 1.1), que imediatamente "reduz", por assim dizer. O riso depois da declaração de que a mediação é difícil pode representar um movimento para se autodefender após admitir alguma fraqueza ou inadequação; representa de facto uma inversão da escalada da tensão, um movimento para desdramatizar o que poderia parecer, por exemplo, exagerado ou não-sério. Em qualquer caso, a tentativa de Butoyi de atingir um co-entendimento é atenuada pelo movimento de se proteger da crítica. A narrativa biográfica corre sempre o risco de ser mal compreendida. A co-construção é o objetivo. Mas nem sempre é o resultado.

Assim, a biografia é construída sobre horizontes da vida e utiliza recursos de experiência, assentes em "camadas" ou "estratos" que representam "reservas de sentido ou de significado" (Dausien, 1996). A entrevista biográfica, que permite contar a história da mudança da vida, abre também um espaço para a reflexão. Assim, Butoyi relaciona o choque do seu primeiro contacto com as práticas de mediação no terreno, expressa as suas dúvidas e reconhece o desafio que a mediação representa, para além de oferecer vislumbres da sua experiência biográfica relacionada com a prática enquanto mediadora que tem todas as componentes de uma teoria de um evento (ver Capps \& Ochs, 1995). O contexto da investigação oferece de facto o "palco" no qual se relaciona a ação biográfica, "reescrita" (metaforicamente), contextualizada e construída.

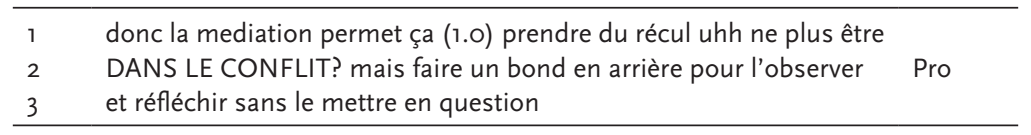

Tabela 11: Excerto 10

Butoyi é capaz de chegar à conclusão, a partir da sua experiência na comunidade de prática representada pelo período de tempo partilhado com os mediadores que participaram com ela no projeto CreE-A, que realmente consegue ver que tem lugar na área da mediação social. 
$\begin{array}{ll}\text { moi je (.) cette année de spécialisation que j'ai faite et même surtout } & \\ \text { le projet creea m'a premise de comprendre que VOILÀ au depart (.) } & \text { Pro } \\ \text { au depart je me suis dit que je suis pas capable moi à résoudre les } & \text { ESp } \\ \text { conflits des gens NON ça semblait impossible mais quand même } & \\ \text { être médiatrice c'est une place que je (1.0) peux prendre } & \text { EpD/Atuação }\end{array}$

Tabela 12: Excerto 11

Conseguiu perceber que: "On doit se sentir capable".

\section{Conclusão}

Bourdieu enfatizou as formas de realização da identidade através do uso da linguagem e a forma como a linguagem, por direito próprio, é realizada através de "atos de identidade", os quais nos permitem perceber a produção materializada da linguagem em cada espaço social, nas palavras de Bourdieu, "uma dimensão da hexis física do indivíduo, na qual o mundo social, em todas as suas relações, e o mundo em todas as relações socialmente instruídas se podem expressar". A linguagem, afirma, "é uma técnica do corpo" incluída em todas as relações sociais (Bourdieu, 2001, p. 126).

Com isto em mente, sugiro que a atenção cuidada à linguagem nas conversas nos ajuda a compreender melhor a narrativa biográfica. Uma rigorosa análise da conversa demonstra, segundo o meu argumento, que a linguagem capta alguns dos seguintes pontos:

- os múltiplos contextos de interação;

- a hesitação e circunlocuções da conversa da entrevista;

- o papel da voz na narrativa;

- a memória e a verbalização de um espaço lembrado;

- o timbre da conversa e a memória emocional e histórica das pessoas e instituições;

- as suposições de conhecimento partilhado;

- os discursos tácitos da compreensão mútua, expressos no uso partilhado da linguagem.

Sugiro que o detalhe ganho com o tipo de análise rigorosa aqui utilizada para discutir as narrativas de um mediador pode ser generalizada ao conjunto de uma narrativa biográfica completa. Também pode ser generalizada a outras potenciais narrativas e conversas da(s) mesma(s) pessoa(s). A análise é documentada e está diretamente ligada à transcrição. As evidências linguísticas - também chamadas práticas da linguagem - encontradas numa parte de uma história de vida poderão ser encontradas e ouvidas numa outra qualquer parte dessa história.

Os mediadores que foram entrevistados, e a narrativa da mediadora Butoyi, estão na vanguarda de uma experiência relevante, em contextos de trabalho, aprendizagem, interação social, relações próximas pessoais e intelectuais ou emocionais. A mediação, como afirma Helena Neves Almeida, pressupõe conhecimento, experiência e capacidades profissionais com o potencial de transformar relações pessoais, interindividuais, 
sociais e de comunidade, assim como de construir uma sociedade mais coesa, pacífica, justa e inclusiva (Almeida, 2016, p. 31). O papel e a identidade profissional do mediador presente, e de possíveis mediadores futuros no geral, é por natureza dinâmica, e depende de uma tarefa de (auto)-reconstrução e co-construção em ação e interação com os outros (Silva et al., 2016, p. 94).

Nesta breve e clara discussão de uma seleção de excertos da conversa biográfica de uma mediadora em formação, pode ser ouvida a construção local da ação social/construção do significado social. A construção de um savoir-faire profissional é provisório, necessariamente incompleto, audível e na transcrição, para mim, visivelmente cautelosa, apesar de já explícita no enquadramento do conhecimento novo e da nova atuação.

\section{Tradução: Núria Santos}

\section{REFERÊNCIAS}

Alheit, P. (1983). Alltagsleben. Zur Bedeutung eines gesellschaftlichen "Restphänomens". Frankfurt / Nova lorque: Campus Verlag.

Alheit, P. (1990). Biographizität als Projekt. Der "biographische Ansatz" in der Erwachsenenbildung. Bremen: Universität Bremen.

Alheit, P. (2002). Biographieforschung und Erwachsenenbildung. In M. Kraul \& W. Marotzki (Eds.), Biographische Arbeit. Perspektiven erziehungswissenschaftlicher Biographieforschung (pp. 211-240). Opladen: Leske+Budrich.

Alheit, P. (2006). ,Biografizität' als Schlüsselkompetenz in der Moderne Paper presented at the Universität Flensburg Tagung: "Das Leben gestalten. Biografisch lernen - biografisch lehren", Universität Flensburg. Retirado de http://www.abl-uni-goettingen.de/aktuell/Alheit_Biographizitaet_Schl-uessel_ Flensburg-2006.pdf

Alheit, P. (2018). The concept of "biographicity" as background concept of lifelong learning. Dyskursy mlodych andragogow, 19, 9-22. Retirado de cejsh.icm.edu.pl/cejsh/element/bwmeta1.../c/or_Alheit.pdf

Alheit, P. \& Dausien, B. (2002). Bildungsprozesse über die Lebensspanne und lebenslanges Lernen. In R. Tippelt (Ed.), Handbuch Bildungsforschung (pp. 565-585). Opladen: Leske + Budrich.

Almeida, H. N. (2016). Sustentabilidade da mediação social. Debates e desafios atuais. In A. M. C. Silva, M. d. L. Carvalho \& L. R. Oliveira (Eds.), Sustentabilidade da Mediação Social: processos e práticas (pp. 13-33). Braga: CECS. Retirado de http://www.lasics.uminho.pt/ojs/index.php/cecs_ebooks/article/ view/2321/2237

Bertaux, D. (2005). L'enquête et ses méthodes. Le récit de vie. Paris: Armand Colin.

Bourdieu, P. (2001). Langage et pouvoir symbolique. Paris: Editions de Seuil.

Capps, L. \& Ochs, E. (1995). Constructing panic. The discourse of agoraphobia. Cambridge (MA): Harvard University Press.

Dausien, B. (1996). Biographie und Geschlecht. Opladen: Leske + Budrich.

De Fina, A., Schiffrin, D. \& Bamberg, M. (2006). Introduction. In A. De Fina, D. Schiffrin \& M. Bamberg (Eds.), Discourse and identity (pp. 1-23). Cambridge: Cambridge University Press. 
Demetrio, D. (1995). Raccontarsi. L’autobiografia come cura di sé. Milão: Raffaello Cortina Editore.

Evans, R. (2004). Learning discourse. Learning biographies, embedded speech and discourse identity in students' talk. Frankfurt / Main: Peter Lang.

Fuchs-Heinritz, W. (2000). Biographische Forschung. Eine Einführung in Praxis und Methoden. Wiesbaden: Westdeutscher Verlag.

Goffman, E. (1981). Forms of talk. Oxford: Blackwell.

Gülich, E. \& Mondada, L. (2008). Konversationsanalyse. Eine Einführung am Beispiel des Französischen. Romanistische Arbeitshefte,Vol. 52. Tübingen: Max Niemeyer Verlag.

Günthner, S. (1997). Complaint stories. Constructing emotional reciprocity among women. In H. Kotthoff \& R. Wodak (Eds.), Communicating gender in context (Vol. 42, pp. 179-218). Amesterdão: John Benjamins.

Hoerning, E. M. (1989). Erfahrungen als biographische Ressourcen. In P. Alheit \& E. M. Hoerning (Eds.), Biographisches Wissen. Beiträge zu einer Theorie lebensgeschichtlicher Erfahrung (pp. 148-163). Frankfurt/ Nova lorque: Campus Verlag.

Hoffmann-Riem, C. (1994). Elementare Phänomene der Lebenssituation. Ausschnitte aus einem Jahrzehnt soziologischen Arbeitens. Weinheim: Deutscher Studien Verlag.

Linde, C. (1993). Life stories. The creation of coherence. Nova lorque /Oxford: Oxford University Press.

Luckmann, T. (1981). Lebenslauf und Sprache. In J. Matthes, A. Pfeifenberger \& M. Stosberg (Eds.), Biographie in handlungswissenschaftlicher Perspektive. Kolloquium am Sozialwissenschaftlichen Forschungszentrum der Universität Erlangen-Nürnberg (pp. 55-66). Nürnberg: Verlag der Nürnberger Forschungsvereinigung e.V.

Merrill, B. \& West, L. (2009). Using biographical methods in social research. Londres: Sage.

Miller, G. (1994). Toward ethnographies of institutional discourse: proposals and suggestions. In G. Miller \& R. Dingwall (Eds.), Context and method in qualitative research (pp. 155-17). Londres: Sage.

Ochs, E. (1979). Transcription as theory. In E. Ochs \& B. B. Schieffelin (Eds.), Developmental pragmatics (pp. 43-72). Nova lorque: Academic Press.

Ochs, E. \& Capps, L. (2001). Living narrative. Creating lives in everyday storytelling. Cambridge (MA): Harvard University Press.

Pavlenko, A. (2007). Autobiographic narratives as data in Applied Linguistics. Applied Linguistics, 28(2), 163188. https://doi.org/10.1093/applin/ammoo8

Pineau, G. (1996). Les histoires de vie comme art formateur de l'existence. Pratiques de formations/Analyses, $31,65-80$.

Pineau, G. \& Le Grand, J.-L. (2007). Les histoires de vie. Paris: Presses Universitaires de France.

Ricoeur, P. (1995). Réflexion faite. Autobiographie intellectuelle. Paris: Editions Esprit.

Schegloff, E. A., Ochs, E. \& Thompson, S. A. (1996). Introduction. In E. Ochs, E. A. Schegloff \& S. A. Thompson (Eds.), Interaction and grammar (pp. 1-51). Cambridge: Cambridge University Press.

Schiffrin, D. (2006). From linguistic reference to social reality. In A. De Fina, D. Schiffrin \& M. Bamberg (Eds.), Discourse and identity (pp. 103-131). Cambridge: Cambridge University Press. 
Schütze, F. (1975). Sprache soziologisch gesehen. Band II: Sprache als Indikator für egalitäre und nichtegalitäre Sozialbeziehungen. München: Wilhelm Fink Verlag.

Schütze, F. (1976). Zur Hervorlockung und Analyse von Erzählungen thematisch relevanter Geschichten im Rahmen soziologischer Feldforschung. In Arbeitsgruppe Bielefelder Soziologen (Eds.), Kommunikative Sozialforschung (pp. 159-261). München: Wilhelm Fink Verlag.

Schütze, F. (1981). Prozeßstrukturen des Lebenslaufs. In J. Matthes, A. Pfeifenberger \& M. Stosberg (Eds.), Biographie in handlungswissenschaftlicher Perspektive. Kolloquium am Sozialwissenschaftlichen Forschungszentrum der Universität Erlangen-Nürnberg (pp. 67-157). Nürnberg: Verlag der Nürnberger Forschungsvereinigung e.V.

Silva, A. M. C., Carvalho, M. d. L. \& Aparicio, M. (2016). Formação, profissionalização e identidade dos mediadores sociais. In A. M. C. Silva, M. d. L. Carvalho \& L. R. Oliveira (Eds.), Sustentabilidade da Mediação Social: processos e práticas (pp. 93-104). Braga: CECS. Retirado de http://www.lasics.uminho. pt/ojs/index.php/cecs_ebooks/article/view/2326/2242

Silva, A. M. C., Carvalho, M. d. L., Moisan, A. \& Fortecöef, C. (2017). Arlekin: a collaborative action-researchtraining project without frontiers. International Research Journal of Human Resources and Social Sciences, 4(3), 66-87. Retirado de http://aarf.asia/hr2.php?p=Volume4,Issue3,March2017

Szczepek Reed, B. (2011). Analyzing conversation. An introduction to prosody. Basingstoke: Palgrave.

Tannen, D. (2007). Talking voices. Repetition, dialogue, and imagery in conversational discourse, Vol. 25. Cambridge: Cambridge University Press.

\section{NOTA BIOGRÁFICA}

Rob Evans, nascido em Londres, vive em Duisburg e é professor de Inglês Acadêmico e Inglês Comercial na Otto-von-Guericke-Universität Magdeburg, Alemanha desde 2004. Estudou Russo e História em Leeds e Tübingen. Vive e trabalha fora do Reino Unido há mais de 40 anos, na Alemanha, Itália e Egito. Os seus interesses de investigação são os métodos biográficos de pesquisa e os discursos de aprendizagem. Editou livros sobre o mundo global / local e aprendizagem de adultos (2009, 2010, 2016), sobre métodos de pesquisa biográfica (2016). Colabora como editor e revisor em várias revistas europeias.

ORCID: 0000-0003-1168-4121

Email: rob.evans@ovgu.de

Morada: Language Centre, English Department, Otto-von-Guericke-Universität Magdeburg, G40C-253 - Zschokkestr. 32, 39104 Magdeburg -Deutschland

\section{* Submetido: 31/01/2019 \\ * Aceite: 04/03/2019}

